\title{
Prevalence of Metabolic Syndrome and Impaired Glucose Metabolism among 10- to 17-Year-Old Overweight and Obese Lithuanian Children and Adolescents
}

\author{
Natalija Smetanina ${ }^{a}$ Raimondas Valickas $^{b}$ Astra Vitkauskiene ${ }^{c}$ \\ Kerstin Albertsson-Wikland ${ }^{d}$ Rasa Verkauskiene ${ }^{a}$ \\ a Institute of Endocrinology, Medical Academy, Lithuanian University of Health Sciences, Kaunas, Lithuania; \\ ${ }^{b}$ Department of Radiology, Medical Academy, Lithuanian University of Health Sciences, Kaunas, Lithuania; \\ 'Department of Laboratory Medicine, Medical Academy, Lithuanian University of Health Sciences, Kaunas, \\ Lithuania; ${ }^{d}$ Department of Physiology/Endocrinology, Institute of Neuroscience and Physiology, Sahlgrenska \\ Academy, Gothenburg University, Gothenburg, Sweden
}

\section{Keywords}

Obesity · Overweight · Insulin resistance $\cdot$ Lipid profile .

Metabolic syndrome $\cdot$ Children · Adolescents · Waist circumference

\begin{abstract}
Background: Overweight (Ow) and obesity among adults and children increases the risk of metabolic consequences. Metabolic syndrome (MS) and impaired glucose metabolism are well-known risk factors for cardiovascular diseases and type 2 diabetes. The aim of this study was to evaluate the prevalence of MS and impaired glucose metabolism among Ow and obese (Ob) children and adolescents (aged 10-17 years) in Lithuania, and to evaluate the associations between insulin resistance (IR) indices and anthropometric parameters as well as metabolic disturbances. Methods: The study population consisted of $344 \mathrm{OwOb}$ children and adolescents of all pubertal stages. Oral glucose tolerance tests (OGTTs), IR and $\beta$ cell function indices, lipid profile, and anthropometric parameters of all subjects were analyzed. MS was defined according to the International Diabetes Federation consensus guidelines. Results: MS was found in $21.3 \%$ of the OwOb children and adolescents, and $12.1 \%$ had impaired glucose
\end{abstract}

karger@karger.com www.karger.com/ofa

Karger $\stackrel{\text { ' }}{5}$

GOPEN ACCESS
(C) 2021 The Author(s)

Published by S. Karger AG, Basel

This is an Open Access article licensed under the Creative Commons Attribution-NonCommercial-4.0 International License (CC BY-NC) (http://www.karger.com/Services/OpenAccessLicense), applicable to the online version of the article only. Usage and distribution for commercial purposes requires written permission. metabolism (6.9\% with impaired fasting glucose, $4.5 \%$ with impaired glucose tolerance, and $0.6 \%$ with type 2 diabetes). IR was directly related to body mass index and waist circumference, waist-to-height and waist-to-hip ratios, and sum of skin-fold thicknesses. Children with MS were more insulinresistant, had higher odds ratio for prediabetes and had a more disturbed lipid profile than subjects without MS. Moreover, total cholesterol and low-density lipoprotein cholesterol levels were significantly lower in the more mature OwOb adolescents. Conclusion: MS and lipid profile disturbances are common in OwOb children and adolescents. MS is directly associated with IR. Therefore, OwOb children and adolescents should be carefully followed up for metabolic abnormalities during late childhood as these can persist into adulthood.

(C) 2021 The Author(s)

Published by S. Karger AG, Basel

\section{Introduction}

The cluster of symptoms defined as metabolic syndrome (MS) is known as a risk factor for the development of type 2 diabetes (T2D) and cardiovascular diseases (CVD) in children and adults [1]. Some studies have 
shown direct links between childhood overweight $(\mathrm{Ow})$ and adult metabolic disturbances and cardiovascular risks [1]. Insulin resistance (IR) has also been reported as a key risk factor for CVD and T2D [2].

The prevalence of MS varies in different populations according to age, gender, and ethnic origin, and also depends on the diagnostic criteria used [3]. According to International Diabetes Federation (IDF) criteria [4], the prevalence of MS in Ow adults ranges from 25 to $43.8 \%$ [5].

According to IDF diagnostic criteria, the prevalence of MS varies from $1.9 \%$ in Brazilian to $20.5 \%$ in Chinese Ow children and adolescents [6-11]. The prevalence of MS in obese $(\mathrm{Ob})$ children is reported to be considerably higher, from $3.7 \%$ in Chinese to $44.0 \%$ in US children and adolescents $[6,7,9-25]$.

The prevalence of impaired glucose metabolism varies from $18.1 \%$ in the UK to $32 \%$ in Kuwait in Ow adults [5, $26,27]$, and from $7.0 \%$ in Spanish to $12.6 \%$ in German OwOb children and adolescents $[5,28,29]$.

Luksiene et al. [30] found a prevalence of MS in Lithuanian men and women (35-64 years of age) of 29.7 and $35.1 \%$, respectively. A recently published study showed that the prevalence of Ow and obesity in children and adolescents (7-17 years of age) in Lithuania is 12.6 and $4.1 \%$, respectively [31]. To date, there are no data on metabolic disturbances in $\mathrm{OwOb}$ children and adolescents in Lithuania.

The aim of this study was to determine the prevalence of MS and impaired glucose metabolism (impaired fasting glucose [IFG], impaired glucose tolerance [IGT], and T2D) in OwOb Lithuanian children and adolescents aged 10-17 years and to evaluate the associations with IR and metabolic disturbances.

\section{Materials and Methods}

\section{Materials}

The study population included $344 \mathrm{Ow}$ (body mass index standard deviation score [BMI-SDS] 1.0-1.99 for gender and age), $\mathrm{Ob}$ (BMI-SDS 2.0-2.99 for gender and age), and morbidly Ob (BMISDS $\geq 3.0$ for gender and age) prepubertal and pubertal (stages 1-5) children aged 10-17 years from the Kaunas region, Lithuania. Children and adolescents involved in the school survey and/or consulted for Ow/obesity at the Department of Endocrinology, Hospital of Lithuanian University of Health Sciences, were recruited for the study over a 3-year period (from January 2012 to April 2014).

The measurements were performed with standardized equipment. Height was measured to the nearest $0.1 \mathrm{~cm}$ with a portable SECA stadiometer $\left(\right.$ Seca $\left.{ }^{\circledR} 214\right)$. Weight was measured to the nearest $0.1 \mathrm{~kg}$ using portable SECA electronic scales (Seca $\left.{ }^{\circledR} 813\right)$. BMI was calculated by using the standard equation: $\mathrm{BMI}=$ weight $(\mathrm{kg}) /$ height $\left(\mathrm{m}^{2}\right)$. Waist circumference (WC), hip, middle thigh and middle arm on the left side, to the nearest $0.1 \mathrm{~cm}$, were measured with nonelastic tape.

Blood pressure was measured in a sitting position after the child had been relaxing for 5-10 min. Measurements were taken twice at intervals of 2-3 min with an automatic device with a special pediatric cuff. The lowest value was used in the analysis. Evaluation of arterial hypertension was defined according to the American Academy of Pediatrics updated guidelines for children and adolescents [32].

Puberty staging for girls was determined by pubarche and breast stage according to Emmanuel and Bokor [33]. In boys, the pubertal stage was determined by pubarche and testicular volume $(<4,4-8,9-12,15-20$, and $>20 \mathrm{~mL}$ represented stages $1-5$, respectively), using a Prader orchidometer.

$\mathrm{BMI}$ and WC measurements were converted to $Z$ scores according to International Obesity Task Force references for BMI [34] and Polish references for WC in boys and girls aged 5-19 years [35].

\section{Laboratory Measurements and Evaluation}

All study participants underwent a clinical examination and an oral glucose tolerance test (OGTT). All blood samples for analysis were collected after $\mathrm{a} \geq 8$ - $\mathrm{h}$ fast. A standard OGTT was performed with oral $1.75 \mathrm{~g} / \mathrm{kg}$ glucose challenge ( $\max .75 \mathrm{~g}$ ) following blood sampling for glycemia and insulin concentrations analysis at 0,30 , and 120 min after glucose load. A fasting lipid profile was assessed by a standard procedure in the biochemistry lab by enzyme-linked immunosorbent assay (ELISA; Instrumentation Laboratory, Lexington, KY, USA); the intra-/interassay coefficient of variation (CV) for total cholesterol (TCh), low-density lipoprotein cholesterol (LDL), high-density lipoprotein cholesterol (HDL), and triglycerides was $1.8 / 1.8 \%, 1.2 / 2.6 \%, 3.2 / 2.0 \%$, and $1.2 / 2.3 \%$, respectively. Serum insulin concentration was measured in a certified clinical lab by radioimmune assay (RIA; DIAsource, Belgium); the intra-/interassay CV was 1.8/6.3\%.

\section{Impaired Glucose Metabolism}

Impaired glucose metabolism included IFG, IGT, and T2D diagnosed according to International Society for Pediatric and Adolescent Diabetes (ISPAD) criteria [36]:

- IFG: fasting plasma glucose $5.6-6.9 \mathrm{mmol} / \mathrm{L}$;

- IGT: 2-h postload glucose 7.8-11.1 $\mathrm{mmol} / \mathrm{L}$;

- T2D: OGTT: fasting plasma glucose $\geq 7.0 \mathrm{mmol} / \mathrm{L}$ and/or $2-\mathrm{h}$ postload glucose $\geq 11.1 \mathrm{mmol} / \mathrm{L}$; randomly fixed on 2 different occasions if asymptomatic or once if presenting symptoms of T2D: fasting plasma glucose $\geq 7.0 \mathrm{mmol} / \mathrm{L}$ and/or casual plasma glucose $\geq 11.1 \mathrm{mmol} / \mathrm{L}$.

\section{Metabolic Syndrome}

MS was diagnosed according to the IDF consensus for children and adolescents [4].

Children Aged 10-16 Years. Obesity according to WC $\geq 90$ th percentile (or adult cut-off if lower) plus any 2 of the following:

- Triglycerides: $\geq 1.7 \mathrm{mmol} / \mathrm{L}$;

- HDL: $<1.03 \mathrm{mmol} / \mathrm{L}$;

- Blood pressure: $\geq 130 \mathrm{~mm} \mathrm{Hg}$ systolic or $\geq 85 \mathrm{~mm} \mathrm{Hg}$ diastolic;

- Fasting plasma glucose: $\geq 5.6 \mathrm{mmol} / \mathrm{L}$ or known T2D.

Adolescents Aged $>16$ Years. Existing IDF criteria for adults were used, i.e., central obesity (BMI $>30$ or WC $>94 \mathrm{~cm}$ in males and $>80 \mathrm{~cm}$ in females) plus any 2 of the following: 
Table 1. Comparison of characteristics of the study population between males and females by weight status

\begin{tabular}{|c|c|c|c|c|c|c|}
\hline & \multicolumn{3}{|l|}{ Overweight } & \multicolumn{3}{|l|}{ Obese $^{\mathrm{a}}$} \\
\hline & males $(16.9 \%)$ & females $(83.1 \%)$ & $p$ value & males $(49.3 \%)$ & females $(50.7 \%)$ & $p$ value \\
\hline Subjects & $n=11$ & $n=49$ & & $n=97(\mathrm{Ob}) ; n=43(\mathrm{mOb})$ & $n=128(\mathrm{Ob}) ; n=16(\mathrm{mOb})$ & \\
\hline Age, years & $12.4 \pm 2.2$ & $14.3 \pm 2.1$ & 0.015 & $13.2 \pm 2.0$ & $13.5 \pm 2.0$ & 0.234 \\
\hline BMI-SDS $^{\mathrm{b}}$ & $1.86 \pm 0.1$ & $1.71 \pm 0.2$ & 0.031 & $2.81 \pm 0.4$ & $2.61 \pm 0.4$ & $<0.0001$ \\
\hline WC-SDS*** & $1.02 \pm 0.3$ & $1.27 \pm 0.4$ & 0.049 & $2.05 \pm 0.4$ & $2.02 \pm 0.3$ & 0.436 \\
\hline $\mathrm{WC}, \mathrm{cm}$ & $76.4 \pm 4.5$ & $78.7 \pm 5.4$ & 0.212 & $94.2 \pm 10.3$ & $89.8 \pm 8.8$ & $<0.0001$ \\
\hline WHtR & $0.48 \pm 0.03$ & $0.48 \pm 0.03$ & 0.896 & $0.57 \pm 0.05$ & $0.55 \pm 0.04$ & 0.0001 \\
\hline WHpR & $0.84 \pm 0.06$ & $0.79 \pm 0.05$ & 0.013 & $0.91 \pm 0.17$ & $0.82 \pm 0.05$ & $<0.0001$ \\
\hline SSFT, mm & $71.5 \pm 14.3$ & $81.4 \pm 15.9$ & 0.076 & $104.4 \pm 21.9$ & $106.4 \pm 22.6$ & 0.469 \\
\hline
\end{tabular}

Ob, obese; mOb, morbidly obese; BMI-SDS, body mass index standard deviation score; WC-SDS, waist circumference standard deviation score; WHtR, waist-to-height ratio; WHpR, waist-to-hip ratio; SSFT, sum of skin-fold thicknesses.

${ }^{\mathrm{a}}$ Included $\mathrm{Ob}$ and $\mathrm{mOb}$ participants.

${ }^{b}$ Evaluated according to IOTF standards [34].

${ }^{c}$ Evaluated according to the Polish reference for WC [35].

- Increased triglycerides: $\geq 1.7 \mathrm{mmol} / \mathrm{L}$, or specific treatment for this lipid abnormality;

- Reduced HDL: $<1.03 \mathrm{mmol} / \mathrm{L}$ in males and $<1.29 \mathrm{mmol} / \mathrm{L}$ in females, or specific treatment for this lipid abnormality;

- Increased blood pressure: systolic $\geq 130 \mathrm{~mm} \mathrm{Hg}$, or diastolic $\geq 85$ $\mathrm{mm} \mathrm{Hg}$, or treatment of previously diagnosed hypertension;

- Raised fasting plasma glucose: $\geq 5.6 \mathrm{mmol} / \mathrm{L}$ or previously diagnosed T2D.

\section{Insulin Resistance}

IR was evaluated using the homeostasis model assessment of insulin resistance (HOMA-IR): fasting plasma glucose in $\mathrm{mmol} / \mathrm{L}$ $\times$ fasting insulin in $\mathrm{mIU} / \mathrm{L} / 22.5$ [37]; homeostasis model assessment of $\beta$ cell function (HOMA-B): $20 \times$ fasting insulin in $\mu \mathrm{U} / \mathrm{mL} /$ fasting glucose in $\mathrm{mmol} / \mathrm{L}-3$; and quantitative insulin sensitivity index (QUICKI): $1 /\left(\log _{\text {insulin }}\right.$ in $\mu \mathrm{U} / \mathrm{mL}+\log _{\text {glucose }}$ in $\mathrm{mg} / \mathrm{dL}$ ) [38]. Insulin secretion was assessed using the insulinogenic index (IGI): $\delta_{\text {insulin }}(0-30 \mathrm{~min}) / \delta_{\text {glucose }}(0-30 \mathrm{~min})$ [38]. Using the standard formulae [39-41], insulin sensitivity (IS) indices (modified by Gutt et al. [41]) were calculated.

For further analysis, the study population was divided into groups according to weight status: Ow, Ob, and morbidly Ob. IR status was defined by HOMA-IR tertiles; individuals with HOMAIR $<2.96$ were attributed to the first tertile, HOMA-IR between 2.96 and 4.46 to the second, and HOMA-IR $>4.46$ to the third.

The prevalence of lipid profile abnormalities in triglycerides and HDL was evaluated according to IDF guidelines for MS in children and adolescents [4]. TCh and LDL concentrations were evaluated according to the US National Heart, Lung and Blood Institute (NHLBI) criteria for dyslipidemias in adolescents [42].

\section{Statistical Analyses}

Statistical analyses were performed using SPSS software 20.0. ANOVA was used to compare means between groups with and without MS, adjusted for BMI-SDS, gender, and pubertal stage. One-way between-group ANOVA with the post hoc Turkey test was used for comparing HOMA-IR tertile groups. Statistical sig- nificance was set at $p<0.05$. Cutoff values for HOMA-IR were calculated by receiver-operating characteristics (ROC) analysis.

To compare our results with those of other studies, we performed a target search (scoping review) in PubMed, using the following key words: children, adolescents, overweight, obesity, and metabolic syndrome. The initial search highlighted 1,658 articles. In the literature review, we included articles similar to our study with regard to the age and weight status of subjects, diagnostic criteria for MS according to IDF, glucose metabolism evaluation according to ISPAD, and biochemical parameters.

\section{Results}

The study population included children and adolescents of all pubertal stages, $43.9 \%$ were males, mean age was $13.5 \pm 2.0$ years, and mean BMI and BMI-SDS $29.8 \pm$ 4.4 and $2.54 \pm 0.5$, respectively. The detailed characteristics of the study population by gender and weight status are presented in Table 1.

The time point of recruitment did not influence the study results: BMI-SDS ( $2.48 \pm 0.5$ vs. $2.55 \pm 0.6$ vs. 2.57 \pm 0.5 in 2012 vs. 2013 vs. 2014 groups, $p=0.07$ between 2012 and 2013 groups; $p=0.87$ between 2013 and 2014 groups, respectively), WC-SDS ( $1.96 \pm 0.5$ vs. $1.82 \pm 0.6$ vs. $1.81 \pm 0.5$ in 2012 vs. 2013 vs. 2014 groups, $p=0.32$ between 2012 and 2013 groups; $p=0.093$ between 2013 and 2014 groups, respectively) and HOMA-IR (4.05 \pm 1.9 vs. $4.22 \pm 2.2$ vs. $4.74 \pm 1.7$ in 2012 vs. 2013 vs. 2014 groups, $p=0.26$ between 2012 and 2013 groups; $p=0.32$ between 2013 and 2014 groups, respectively) did not differ by season and year of recruitment. 
Fig. 1. Prevalence of metabolic syndrome for males and females by weight status. Values are in percentages. ${ }^{*} p<0.05$ in comparison with overweight females. Overweight: BMI-SDS 1.0-1.99; obesity: BMI-SDS 2.0-2.99; morbid obesity: BMISDS 23.0. BMI-SDS, body mass index standard deviation score evaluated according to IOTF standards [34].

Table 2. Comparison of characteristics between overweight / obese children with MS and without MS (adjusted for gender, BMI-SDS, and pubertal stage)

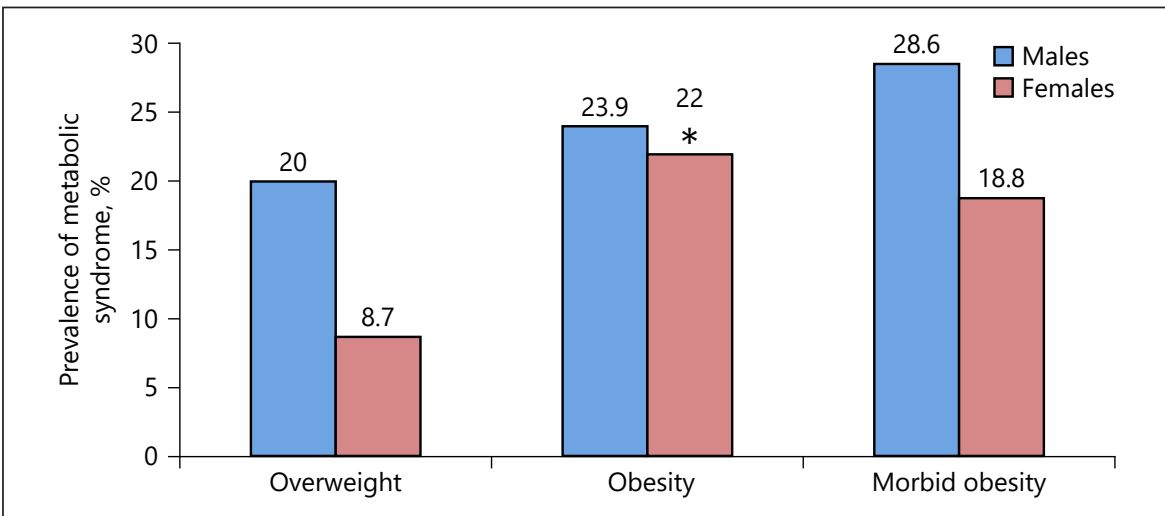

\begin{tabular}{|c|c|c|c|}
\hline & With MS & Without MS & $p$ value \\
\hline BMI-SDS $^{\mathrm{a}}$ & $2.68 \pm 0.5$ & $2.51 \pm 0.6$ & $<0.0001$ \\
\hline WC-SDS ${ }^{\mathrm{b}}$ & $2.08 \pm 0.5$ & $1.86 \pm 0.5$ & $<0.0001$ \\
\hline $\mathrm{WC}, \mathrm{cm}$ & $95.0 \pm 10.8$ & $88.4 \pm 10.0$ & $<0.0001$ \\
\hline WHtR & $0.56 \pm 0.06$ & $0.54 \pm 0.05$ & $<0.0001$ \\
\hline WHpR & $0.86 \pm 0.07$ & $0.85 \pm 0.14$ & $<0.0001$ \\
\hline SSFT, mm & $108.2 \pm 19.1$ & $99.8 \pm 24.3$ & $<0.0001$ \\
\hline \multicolumn{4}{|l|}{ Glycemia } \\
\hline At $0 \mathrm{~min}, \mathrm{mmol} / \mathrm{L}$ & $5.24 \pm 0.7$ & $5.04 \pm 0.4$ & 0.019 \\
\hline At $30 \mathrm{~min}, \mathrm{mmol} / \mathrm{L}$ & $7.79 \pm 1.5$ & $7.73 \pm 1.4$ & 0.201 \\
\hline At $120 \mathrm{~min}, \mathrm{mmol} / \mathrm{L}$ & $5.73 \pm 1.2$ & $5.67 \pm 1.2$ & 0.017 \\
\hline \multicolumn{4}{|l|}{ Insulin } \\
\hline At $0 \mathrm{~min}, \mathrm{mIU} / \mathrm{L}$ & $22.9 \pm 11.2$ & $16.6 \pm 8.1$ & $<0.0001$ \\
\hline At $30 \mathrm{~min}, \mathrm{mIU} / \mathrm{L}$ & $148.2 \pm 85.2$ & $117.8 \pm 72.0$ & 0.002 \\
\hline At $120 \mathrm{~min}, \mathrm{mIU} / \mathrm{L}$ & $84.8 \pm 72.1$ & $67.6 \pm 56.5$ & 0.026 \\
\hline HOMA-IR & $5.31 \pm 2.9$ & $3.78 \pm 1.9$ & $<0.0001$ \\
\hline QUICKI & $0.132 \pm 0.008$ & $0.139 \pm 0.011$ & $<0.0001$ \\
\hline HOMA-B & $82.8 \pm 40.8$ & $63.4 \pm 31.2$ & $<0.0001$ \\
\hline I/G_30 & $18.8 \pm 9.6$ & $15.3 \pm 8.9$ & $<0.0001$ \\
\hline ISI & $49.1 \pm 22.3$ & $69.4 \pm 39.9$ & $<0.0001$ \\
\hline ISI $_{\text {Matsuda }}$ & $2.71 \pm 1.2$ & $3.85 \pm 2.2$ & $<0.0001$ \\
\hline ISI $_{\text {Cederholm }}$ & $33.0 \pm 10.4$ & $34.9 \pm 11.5$ & 0.012 \\
\hline ISI $_{\text {Gutt }}$ & $32.2 \pm 9.4$ & $35.3 \pm 10.6$ & 0.009 \\
\hline TCh, mmol/L & $4.64 \pm 1.0$ & $4.48 \pm 0.8$ & $<0.0001$ \\
\hline $\mathrm{LDL}, \mathrm{mmol} / \mathrm{L}$ & $2.95 \pm 0.8$ & $2.77 \pm 0.8$ & 0.001 \\
\hline TG/HDL ratio & $1.85 \pm 1.2$ & $0.85 \pm 0.7$ & $<0.0001$ \\
\hline LDL/HDL ratio & $3.05 \pm 1.0$ & $2.52 \pm 1.7$ & 0.020 \\
\hline
\end{tabular}

Values are mean \pm SD. MS, metabolic syndrome; BMI-SDS, body mass index standard deviation score; WC-SDS, waist circumference standard deviation score; WHtR, waist-toheight ratio; WHpR, waist-to-hip ratio; SSFT, sum of skin-fold thicknesses; HOMA-IR, homeostasis model assessment of insulin resistance; QUICKI, quantitative insulin sensitivity index; HOMA-B, homeostasis model assessment of $\beta$ cell function; ISI, insulin sensitivity index; I/G_30, insulin/glucose at $30 \mathrm{~min}$ of OGTT;OGTT, oral glucose tolerance

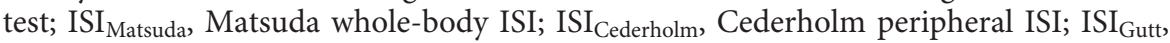
Gutt ISI; TCh, total cholesterol; LDL, low-density lipoprotein cholesterol; HDL, highdensity lipoprotein cholesterol; TG, triglycerides.

${ }^{\text {a }}$ Evaluated according to IOTF standards [34].

${ }^{\mathrm{b}}$ Evaluated according to the Polish reference for WC [35]. 
Fig. 2. Prevalence of impaired glucose metabolism in overweight / obese males and females with different HOMA-IR tertiles. ${ }^{*} p<0.001$. HOMA-IR, homeostasis model assessment of insulin resistance. 1st HOMA-IR tertile: <2.96; 2nd HOMA-IR tertile: $2.96-4.46$; 3 rd HOMA-IR tertile: $>4.46$.
Fig. 3. HOMA-IR correlation with BMISDS in overweight / obese children and adolescents (mean, 95\% confidence interval [CI]); $r=0.30, p<0.0001$.
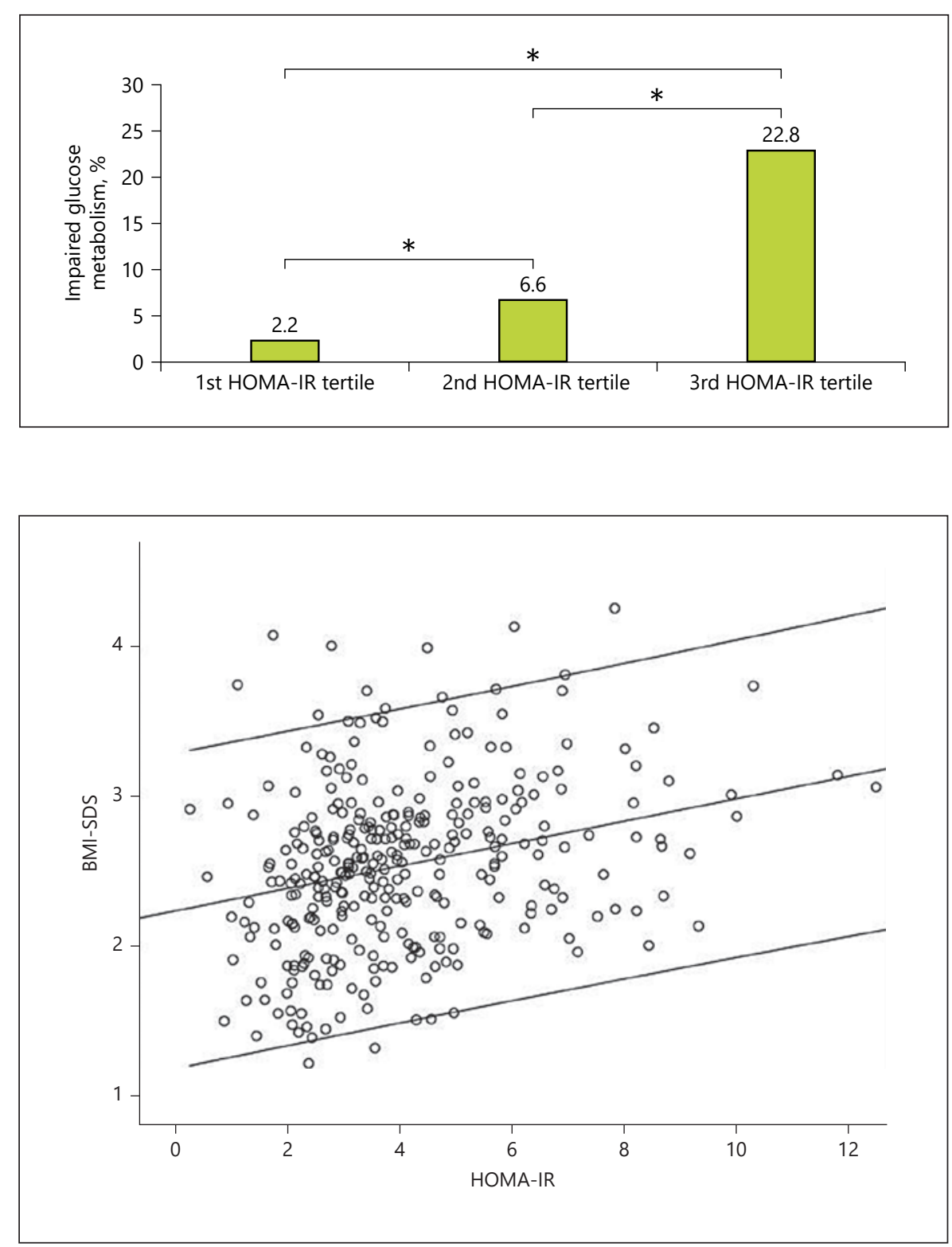

\section{Metabolic Syndrome}

We found a prevalence of MS of 21.3\% in OwOb children and adolescents. BMI had a direct impact on the prevalence of MS $(10.7,22.8$, and $25.9 \%$ in Ow, Ob, and morbidly Ob children and adolescents, respectively; $p=$ 0.046 between $\mathrm{Ow}$ and $\mathrm{Ob}$ ). MS prevalence in $\mathrm{OwOb}$ boys was $25.0 \%$ compared with $18.4 \%$ in girls $(p>0.5)$.

The distribution of MS between genders in relation to weight status is presented in Figure 1. MS prevalence was significantly higher in $\mathrm{Ob}$ girls than in Ow girls $(p=$ 0.048 ), but did not increase further in morbidly $\mathrm{Ob}$ girls. In males, the occurrence of MS was not related to weight status (Fig. 1). Adjusted for age, the odds ratio (OR) for
MS in Ob versus Ow females was 3.95 (95\% CI 1.25$12.49, p=0.02$ ), but morbid obesity did not further increase the risk of MS (OR 2.59, 95\% CI 0.50-13.41, $p=$ $0.26)$. OR for MS in males was not significant.

MS was significantly more prevalent in children and adolescents with HOMA-IR in the third tertile than in those in the first tertile ( 32.4 and $7.5 \%, p<0.0001$, respectively). Adjusted for age, pubertal stage, and BMI-SDS, the fasting glucose and insulin levels, HOMA-IR, HOMA$\mathrm{B}, \mathrm{TCh}$, and LDL were significantly higher in children with MS than in their counterparts without MS (Table 2).

Adjusted for BMI, pubertal stage, and height, systolic blood pressure was significantly higher in boys than in 
Fig. 4. HOMA-IR values according to glucose metabolism type in overweight / obese children and adolescents (mean, CI). ${ }^{*} p<$ 0.05 .

Table 3. Comparison of parameters between the overweight / obese children and adolescents from the first and third HOMA-IR tertiles

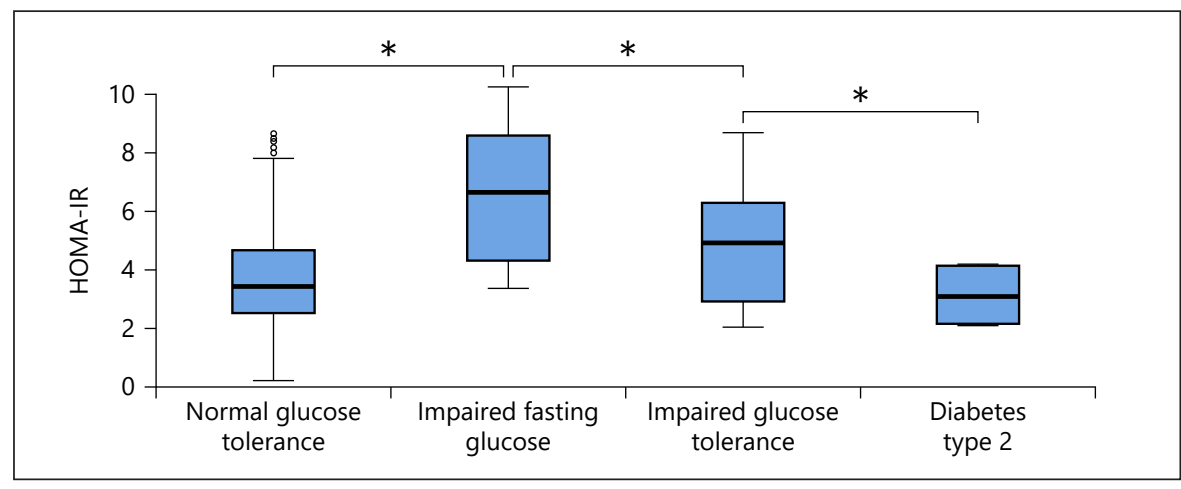

\begin{tabular}{lccc}
\hline & $1^{\text {st }}$ tertile & $3^{\text {rd }}$ tertile & $p$ value \\
\hline BMI-SDS $^{\mathrm{a}}$ & $2.33 \pm 0.6$ & $2.75 \pm 0.6$ & $<0.0001$ \\
WC-SDS $^{\mathrm{b}}$ & $1.68 \pm 0.5$ & $2.11 \pm 0.4$ & $<0.0001$ \\
WHpR & $0.85 \pm 0.07$ & $0.88 \pm 0.2$ & $<0.0001$ \\
WHtR & $0.53 \pm 0.05$ & $0.56 \pm 0.05$ & $<0.0001$ \\
SSFT, mm & $91.2 \pm 21.3$ & $112.7 \pm 22.8$ & $<0.0001$ \\
Glycemia & & & \\
$\quad$ At 0 min, mmol/L & $4.92 \pm 0.3$ & $5.28 \pm 0.5$ & $<0.0001$ \\
$\quad$ At 30 min, mmol/L & $7.72 \pm 1.5$ & $7.94 \pm 1.4$ & 0.252 \\
$\quad$ At 120 min, mmol/L & $5.51 \pm 1.4$ & $5.91 \pm 1.1$ & $<0.0001$ \\
Insulin & & & \\
$\quad$ At 0 min, mIU/L & $10.1 \pm 2.6$ & $27.7 \pm 8.7$ & $<0.0001$ \\
$\quad$ At 30 min, mIU/L & $84.2 \pm 46.5$ & $165.3 \pm 89.0$ & $<0.0001$ \\
$\quad$ At 120 min, mIU/L & $45.9 \pm 36.3$ & $105.0 \pm 80.0$ & $<0.0001$ \\
TCh, mmol/L & $4.52 \pm 0.8$ & $4.57 \pm 0.9$ & 0.001 \\
TG, mmol/L & $0.88 \pm 0.6$ & $1.29 \pm 0.7$ & $<0.0001$ \\
LDL, mmol/L & $2.77 \pm 0.8$ & $2.88 \pm 0.8$ & 0.002 \\
HDL, mmol/L & $1.21 \pm 0.3$ & $1.14 \pm 0.3$ & 0.012 \\
Systolic BP, mm Hg & $116.8 \pm 13.4$ & $120.8 \pm 16.4$ & $<0.0001$ \\
Diastolic BP, mm Hg & $72.3 \pm 8.7$ & $75.5 \pm 9.5$ & 0.002 \\
\hline
\end{tabular}

Values are mean \pm SD. BMI-SDS, body mass index standard deviation score; WC-SDS, waist circumference standard deviation score; WHtR, waist-to-height ratio; WHpR, waistto-hip ratio; SSFT, sum of skinfold thicknesses; TCh, total cholesterol; TG, triglycerides; LDL, low-density lipoprotein cholesterol; HDL, high-density lipoprotein cholesterol; BP, blood pressure.

${ }^{\text {a }}$ Evaluated according to IOTF standards [34].

${ }^{\mathrm{b}}$ Evaluated according to the Polish reference for WC [35].

${ }^{\mathrm{c}}$ Adjusted by height. girls (121.6 \pm 15.3 and $118.7 \pm 14.6 \mathrm{~mm} \mathrm{Hg}$, respectively; $p<0.0001$ ), but diastolic blood pressure was significantly higher in girls than in boys $(74.0 \pm 9.2$ and $73.2 \pm 8.6 \mathrm{~mm}$ $\mathrm{Hg}$, respectively; $p=0.003)$. MS comorbidity analysis showed that $74.3 \%$ of individuals with MS had arterial hypertension, $45.7 \%$ had increased triglycerides, $25.7 \%$ had increased LDL, and $65.7 \%$ had decreased HDL. MS in $\mathrm{OwOb}$ children and adolescents significantly increased the risk for arterial hypertension (OR 5.64, 95\% CI 3.11$10.25, p<0.0001)$. Increased systolic or diastolic blood pressure was found in 60.0 and $41.4 \%$ of OwOb subjects with MS, respectively.

\section{IR and Glucose Metabolism}

Analyses of IR revealed that children and adolescents in the third HOMA-IR tertile had a significantly higher prevalence of impaired glucose metabolism than those in the first and second HOMA-IR tertiles (Fig. 2).

HOMA-IR was significantly directly related to BMISDS (Fig. 3), WC-SDS ( $r=0.36, p<0.001)$, sum of skin- 
Fig. 5. Insulin resistance according to pubertal stage and sex. ${ }^{*} p \leq 0.05,{ }^{* *} p \leq 0.01$, $* * * p \leq 0.005$.

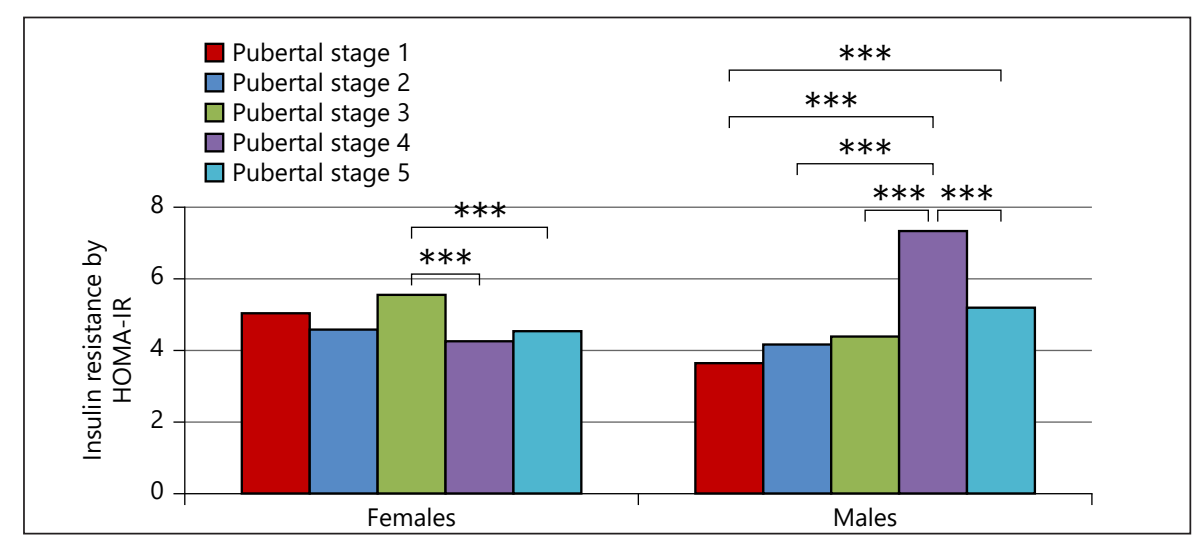

fold thicknesses $(r=0.34, p<0.001)$, and triglyceride levels $(r=0.21, p<0.001)$.

Impaired glucose metabolism was detected in $12.1 \%$ of OwOb children and adolescents; $6.9 \%$ had IFG, $4.5 \%$ had IGT, and $0.6 \%$ were diagnosed as having T2D. IGT was more frequent in boys than in girls ( $7.1 \mathrm{vs.} 2.7 \%, p<0.05)$ but girls had a higher prevalence of IFG (8.2 vs. 5.0\%, $p<$ 0.05).

According to different glucose metabolism abnormalities, adjusting for age, gender, and pubertal stages, mean HOMA-IR was highest in children and adolescents with IFG and lowest in those with T2D (vs. subjects with normal glucose metabolism and IGT; $p<0.05$ between all groups; Fig. 4).

There was a significant direct correlation between insulin levels at all 3 time points of OGTT and sum of skinfold thicknesses $(r=0.28, p<0.001 ; r=0.24, p<0.001$; and $r=0.16, p=0.016$, respectively).

Comparison of anthropometric parameters by the groups of HOMA-IR tertiles are presented in Table 3. Adjusting for BMI, pubertal stage, gender, and height, both systolic and diastolic blood pressure were significantly higher in children and adolescents with HOMA-IR in the third tertile than in those in the first tertile (Table 3).

Comparing anthropometric measurements (BMI, BMI-SDS, WC, WC-SDS, sum of skin-fold thicknesses, systolic and diastolic blood pressure) and lipid profiles of the group with normal glucose metabolism and the group with impaired glucose metabolism did not reveal any significant differences.

Interestingly, BMI-SDS-adjusted glucose profile was similar in different pubertal stages in girls. Boys in pubertal stage 4 showed significantly higher fasting glucose than those in stages 1 and $2(5.27 \pm 0.5,5.04 \pm 0.3$, and $4.99 \pm 0.3$, respectively; $p=0.034$ between pubertal stages 1 and 4 and $p=0.021$ between pubertal stages 2 and 4 ).
The highest blood glucose at $2 \mathrm{~h}$ after glucose load was in the prepubertal boys, compared to in boys in pubertal stages 4 and $5(6.09 \pm 1.4,5.73 \pm 1.4$, and $5.39 \pm 1.15$, respectively; $p=0.0011$ between pubertal stages 1 and 4 and $p=0.013$ between pubertal stages 1 and 5).

Comparing the IR by HOMA-IR between pubertal stages showed that IR in males was the highest in pubertal stage 4. Meanwhile, in females, IR decreased significantly during puberty progression from stage 3 to stages 4 and 5 (Fig. 5).

The OR for prediabetes (IFG and IGT) and impaired glucose metabolism in association with MS was 5.76 (95\% CI 2.86-11.60, $p<0.0001)$ and 3.44 (95\% CI 1.71-6.93, $p<0.0001$ ), respectively. ROC analysis showed that HOMAIR in association with MS for both genders had an area under the curve (AUC) of 0.675 (95\% CI 0.62-0.76, $p=0.0001$ ); HOMA-IR 3.12 had $82.4 \%$ sensitivity and $48.1 \%$ specificity. The OR for IR (HOMA-IR > 3.16) in the presence of MS was 3.7 (95\% CI 1.88-7.23, $p=0.0001)$.

\section{Lipid Profile}

Decreased HDL and increased triglyceride, TCh, and LDL levels were found in $37.8,13.4,20.6$, and $18.6 \%$ of the OwOb children and adolescents, respectively. Lipid profile analyses showed a significant decrease in TCh and LDL levels along with puberty progression in both genders (Fig. 6). TCh was highest during pubertal stages 1 and 2, and HDL was highest in prepubertal boys (Fig. 6a). Meanwhile, in girls, TCh, LDL, and triglycerides were significantly higher before puberty and decreased with advancing pubertal stages (Fig. 6b).

TCh and low LDL levels as well as triglycerides/HDL and LDL/HDL ratios were significantly higher in children with MS than in those without MS (Table 2). TCh, LDL, and triglyceride levels were significantly higher and HDL significantly lower in those in the third HOMA-IR tertile than in those in the first tertile (Table 3 ). 
Fig. 6. Lipid profile in overweight / obese subjects according to pubertal stage. a Lipid profile in males. ${ }^{*} p<0.05,{ }^{* *} p<0.005$. b Lipid profile in females. ${ }^{*} p<0.05,{ }^{* *} p<$ 0.005 .

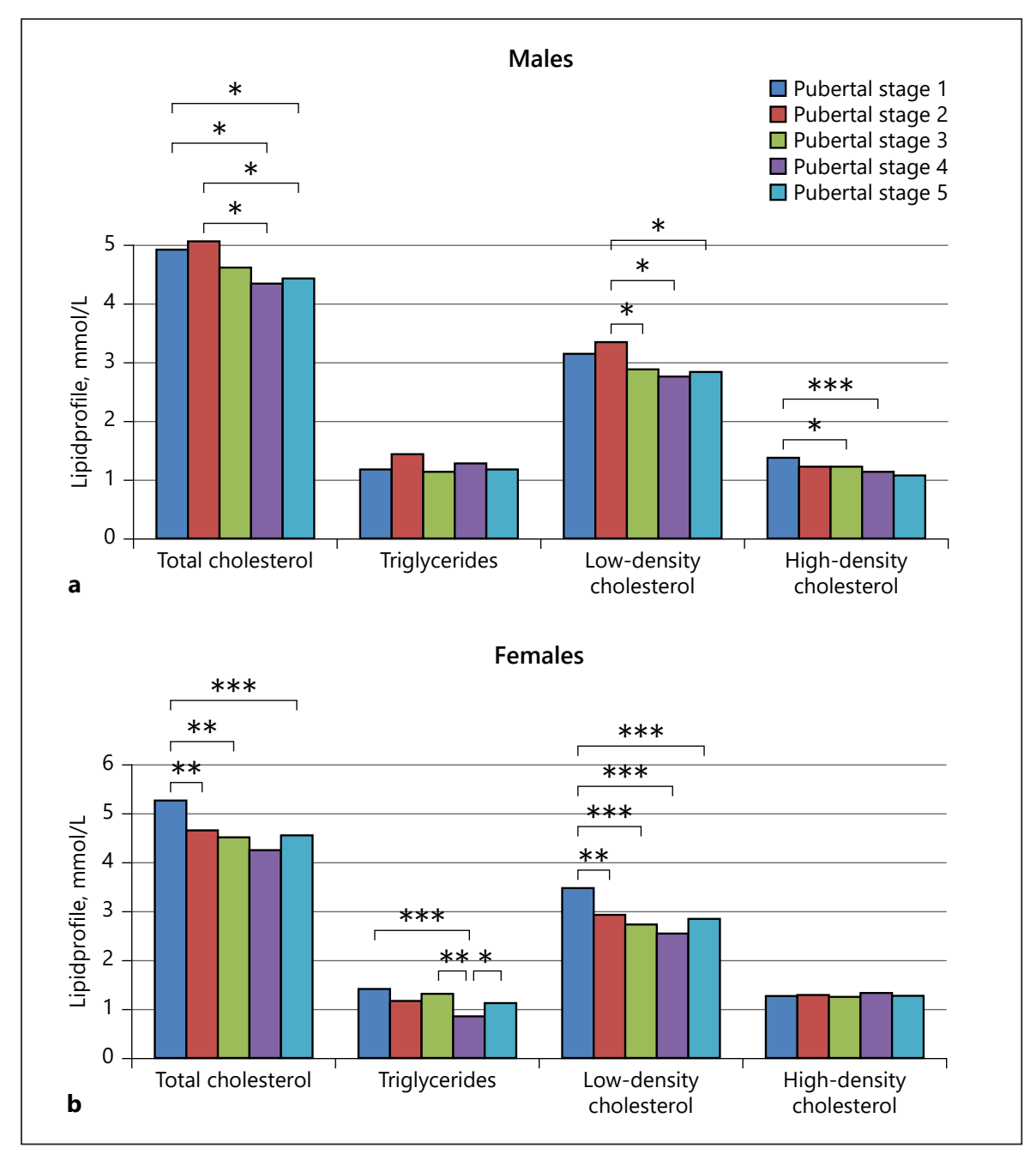

The OR for hypertriglyceridemia in association with MS was 16.77 (95\% CI 8.56-32.85, $p<0.0001$ ), and with decreased HDL 6.95 (95\% CI 3.91-12.35, $p<0.0001$ ), respectively.

\section{Discussion}

One-fifth of the OwOb children and adolescents in our study met the criteria for the presence of MS, which is associated with reduced insulin sensitivity, dyslipidemia, and a higher prevalence of impaired glucose metabolism. This is the first large-scale study in Lithuania to report on metabolic status in $\mathrm{OwOb}$ children and adolescents. To the best of our knowledge, it is also the first study analyzing glucose metabolism and lipid profile according to sex and pubertal stage.
MS Prevalence in $\mathrm{OwOb}$ Children and Adolescents

Dramatically increasing over the last 2 decades, the prevalence of obesity has now flattened out in developed countries [43]. The prevalence of Ow and obesity among children and adolescents in Lithuania is one of the lowest in Europe [44]. Data on the prevalence of MS depend on the criteria used and vary across countries. In general, in our study, the prevalence of MS in a pediatric OwOb population was similar to that reported by previous publications [8, 12-14, 24, 25, 45-48]. However, Druet et al. [8] documented a lower prevalence of MS (15.9\%) in Ob French children aged 9-13 years with a higher prevalence of obesity in France than Lithuania at the time [44].

A recent study by Jung et al. [49] reported that BMI has the best predictive power to identify MS and its components in adolescents. In our study, the $\mathrm{OwOb}$ boys had a higher prevalence of MS than the girls, in agreement with the data in Laurson et al. [50]. This might partly be ex- 
plained by gender differences in the definition of MS between boys and girls for HDL cutoff values. Ervin [51] highlighted a higher prevalence of greater WC and low HDL in females, with a weaker association between BMI status and MS than in males, suggesting the importance of obesity but also other underlying genetic and environmental factors in the development of MS. Girls experience a greater increase in fat mass throughout childhood and puberty than boys, and this is even more pronounced in heavier (than in leaner) girls $[52,53]$; this might, in part, explain the higher risk for developing MS in Ob females than in Ow females. Interestingly, in our study, morbid obesity (vs. Ow) in females does not increase the risk for MS. It has been suggested that adipose tissue has a limited maximal capacity to increase in mass and to store lipids. Adipocyte hyperplasia may present a mechanism for healthy fat storage capacity [54]. This adipose tissue expandability appears to be a more important determinant of obesity-associated metabolic problems than the absolute amount of adipose tissue. It is hypothesized that when a point of maximal expansion of adipose tissue is reached, metabolic complications occur due to the ectopic deposition of excess lipid in nonadipose organs, causing IR via lipid-induced toxicity [55]. Moreover, adipose tissue macrophage infiltration correlates directly with adipocyte size but not with a subject's weight [56]. The resulting changes appear to induce profound consequences for basal systemic inflammation and IS, which are the basal mechanisms underlying MS [57].

\section{$M S$ and $I R$}

The IDF definition of MS does not include IR. However, some studies have highlighted the importance of IR as an independent risk factor that may contribute to the development of CVD [58]. However, data on IR and MS in several previous studies are conflicting $[58,59]$. The most recent National Health and Nutrition Examination Survey (NHANES, 1999-2010) showed a low sensitivity of MS to identify adolescents with IGT [60]. On the other hand, according to the Adult Treatment Panel III (ATPIII) classification, individuals with IGT have significantly higher rates of MS [60]. Juárez-López et al. [2] reported that IR is associated with a higher prevalence of the components of MS.

We found a significantly higher insulin concentration, higher IR indices, and lower IS indices in children and adolescents with MS than in those without MS, not only at baseline but also at all time points of OGTT. Although within the normal range, the mean level of glucose at baseline and the glucose load after $2 \mathrm{~h}$ were also significantly

Prevalence of Metabolic Disturbances in Obese/OW Children and Adolescents higher in subjects with MS; only glycemia at $30 \mathrm{~min}$ of OGTT during the first insulin secretion phase did not reach significance. These findings may partially be influenced by puberty being a challenging period for glucose metabolism and IR. Pubertal IR is associated with lower insulin receptor sensibility or other cofactors, such as dyslipidemia, and upregulates compensatory insulin secretion to be able to keep the glucose concentration at the same peak level at $30 \mathrm{~min}$ of OGTT. Moreover, in the presence of Ow or obesity, pubertal IR may contribute to the eventual development of MS. Similar findings were reported in a Finnish pediatric study where fasting insulin levels were found to be higher in the children who later developed MS [61]. Similarly, in Druet et al. [8], it was found that the likelihood of MS increased strongly along with IR.

In our study, children with MS were not only more insulin-resistant, they also had a 3-fold higher prevalence of impaired glucose metabolism than those without MS. Although this association is partly a consequence of the definition of MS itself, as MS involves IFG and T2D, at the same time, it points to a significant link between MS and IR.

\section{IR and Puberty}

Individuals in the third HOMA-IR tertile were found to have significantly higher insulin levels at all time points of OGTT, and the glucose concentration was significantly higher at the baseline and $2 \mathrm{~h}$ after glucose load. This may reflect a compensatory secretion of insulin due to increasing IR to maintain normal glycemia at $30 \mathrm{~min}$ of OGTT. Assuming that the compensatory scope is insufficient, this may explain the higher frequency of impaired glucose metabolism in the higher HOMA-IR tertiles. We also found a different glucose profile in girls and in boys at different pubertal stages, which may be related to the differences in IS caused by the different levels of genderrelated sex hormones [62].

It is worth noting that the prevalence of IGT was higher in female children and adolescents, but the prevalence of IFG was higher in males. George et al. [63] also reported a higher prevalence of IGT in Ob females than in $\mathrm{Ob}$ males [63]. This strengthens the previous finding that girls are more insulin-resistant than boys in all pubertal stages [64].

\section{IR and Obesity Levels}

Kurtoğlu et al. [65] did not find any significant difference in BMI between the groups with and without IR. In contrast, our study results showed a direct relationship between weight status and IR, with BMI-SDS, WC-SDS, and sum of skin-fold thicknesses scores significantly higher in the children in the third HOMA-IR tertile, i.e., show- 
ing a considerable influence of fat accumulation on the development of IR. Moreover, Pastucha et al. [12] in their study found a relatively high incidence of IR in Ob children, and raised the question of whether the existing diagnostic criteria do not falsely exclude some cases of MS.

\section{MS, Puberty, and the Lipid Profile}

$\mathrm{OwOb}$ children are prone to have dyslipidemia and MS [66]. Compared to the study by Mellerio et al. [67] that involved adolescents with normal weight in whom triglycerides levels increased with age and other lipid fractions showed modest changes during puberty, in our study, TCh in both genders and LDL in girls only was significantly higher in prepubertal children and decreased with the progression of puberty. These results are similar to the study of Pinhas-Hamiel et al. [68], who found lower TCh and LDL levels in Ob adolescents at later stages of puberty, possibly related to the increased secretion of sex steroids and pubertal spurt.

However, TCh and LDL levels were significantly higher in children with MS than in those without MS. Moreover, increased triglyceride and decreased HDL levels were associated with MS. The significantly higher LDL/ HDL ratio in children with MS than in non-MS individuals is similar to the findings of Burns et al. [69], suggesting that this ratio might be a good predictive marker for MS and IR in young people. It could also play a role in the early detection of risk factors for CVD as LDL-cholester$\mathrm{ol}$ is known to have a strong association with coronary artery calcification in adults [70].

Similar to the data published by Vukovic et al. [71], lipid levels were found to be significantly higher in the most insulin-resistant children and adolescents.

This study has some limitations. It was a cross-sectional study that included $\mathrm{Ow}$ and $\mathrm{Ob}$ children and adolescents, but no comparison with normal-weight children was made. Longitudinal follow-up is necessary to establish the cutoffs for risk factors, such as IR, during different stages of puberty, to correct the diagnostic criteria for MS in children and adolescents, i.e., IFG and T2D, but also $\mathrm{IR}$, and to evaluate the associations between risk factors and metabolic consequences.

\section{Conclusions}

In summary, our findings support a strong association between MS and IR. We found MS in one-fifth of the OwOb children and adolescents, i.e., those who were more $\mathrm{Ob}$ and less sensitive to insulin. Impaired glucose metabo- lism was found in $12.1 \%$ of $\mathrm{OwOb}$ children and adolescents, with IGT more frequently in boys and IFG in girls. Children with IFG were the most insulin-resistant.

Every sixth $\mathrm{OwOb}$ child or adolescent (aged 10-17 years) had lipid metabolism abnormalities. Our results confirm that Ow/obesity-related early metabolic disturbances and risk factors for CVD and T2D were found in children and adolescents, and these may be predictive of metabolic status in adulthood. Therefore, $\mathrm{OwOb}$ children should be followed up for early metabolic derangements from childhood onwards.

\section{Acknowledgment}

The authors are grateful to the team of Pediatric endocrinology, especially nurses, from Department of Endocrinology, Hospital of Lithuanian University of Health Science for project assistance; to Jurgita Grigiene from International relations and study center, Lithuanian University of Health Science, for English editing, and to all participants and their parents for attendance to the study.

\section{Statement of Ethics}

All children and their parents signed an informed consent form approved by the Lithuanian Bioethics Committee (BE-2-1, 200901-22; P-13-24, 2013-03-22). Study also registered as EudraCT No. 2011-006352-36.

\section{Conflict of Interest Statement}

The authors have no conflicts of interest to declare.

\section{Funding Sources}

The research was supported by Research Council of Lithuania grant No. MIP-039/2013, Research Foundation for Lithuanian University of Health Sciences, and Swedish governmental university hospital grants (ALF).

\section{Author Contributions}

N.S. contributed to the study design, clinical evaluation of the cohort, and the acquisition, analysis, and interpretation of data; performed statistical analyses; and drafted the manuscript. R.Val. carried out the radiology and clinical evaluation. A.V. carried out the laboratory tests, was involved in data analysis and interpretation. K.A.W. contributed to the study design, data analysis, and interpretation of results. R.Ver. designed, initiated, and coordinated the study, and also helped to draft the manuscript. All authors made an intellectual contribution to the manuscript, revised it critically, and approved the final version for submission. 


\section{References}

1 Gurka MJ, Ice CL, Sun SS, Deboer MD. A confirmatory factor analysis of the metabolic syndrome in adolescents: an examination of sex and racial/ethnic differences. Cardiovasc Diabetol. 2012 Oct;11(1):128.

2 Juárez-López C, Klünder-Klünder M, Medina-Bravo P, Madrigal-Azcárate A, Mass-Díaz E, Flores-Huerta S. Insulin resistance and its association with the components of the metabolic syndrome among obese children and adolescents. BMC Public Health. 2010 Jun;10(1):318.

3 Kassi E, Pervanidou P, Kaltsas G, Chrousos G. Metabolic syndrome: definitions and controversies. BMC Med. 2011 May;9(1):48.

4 Zimmet P, Alberti KG, Kaufman F, Tajima N, Silink M, Arslanian S, et al.; IDF Consensus Group. The metabolic syndrome in children and adolescents - an IDF consensus report. Pediatr Diabetes. 2007 Oct;8(5):299306.

5 Lloyd LJ, Langley-Evans SC, McMullen S. Childhood obesity and risk of the adult metabolic syndrome: a systematic review. Int J Obes. 2012 Jan;36(1):1-11.

6 Tavares Giannini D, Caetano Kuschnir MC, Szklo M. Metabolic syndrome in overweight and obese adolescents: a comparison of two different diagnostic criteria. Ann Nutr Metab. 2014;64(1):71-9.

7 Wang Q, Yin J, Xu L, Cheng H, Zhao X, Xiang $\mathrm{H}$, et al. Prevalence of metabolic syndrome in a cohort of Chinese schoolchildren: comparison of two definitions and assessment of adipokines as components by factor analysis. BMC Public Health. 2013 Mar;13(1):249.

8 Druet C, Dabbas M, Baltakse V, Payen C, Jouret B, Baud C, et al. Insulin resistance and the metabolic syndrome in obese French children. Clin Endocrinol (Oxf). 2006 Jun;64(6):672-8.

9 Liu W, Lin R, Liu A, Du L, Chen Q. Prevalence and association between obesity and metabolic syndrome among Chinese elementary school children: a school-based survey. BMC Public Health. 2010 Dec;10(1):780.

$10 \mathrm{Lim} \mathrm{H}$, Xue H, Wang Y. Association between obesity and metabolic co-morbidities among children and adolescents in South Korea based on national data. BMC Public Health. 2014 Mar;14(1):279.

11 Haroun D, Mechli R, Sahuri R, AlKhatib S, Obeid O, El Mallah C, et al. Metabolic syndrome among adolescents in Dubai, United Arab Emirates, is attributable to the high prevalence of low HDL levels: a cross-sectional study. BMC Public Health. 2018 Nov;18(1):1284.

12 Pastucha D, Filipcikova R, Horakova D, Radova L, Marinov Z, Malincikova J, et al. The incidence of metabolic syndrome in obese Czech children: the importance of early detection of insulin resistance using homeostatic indexes HOMA-IR and QUICKI. Physiol Res. 2013;62(3):277-83.
13 Lafortuna CL, Adorni F, Agosti F, De Col A, Sievert K, Siegfried W, et al. Prevalence of the metabolic syndrome among extremely obese adolescents in Italy and Germany. Diabetes Res Clin Pract. 2010 Apr;88(1):14-21.

14 Cook S, Auinger P, Li C, Ford ES. Metabolic syndrome rates in United States adolescents, from the National Health and Nutrition Examination Survey, 1999-2002. J Pediatr. 2008 Feb;152(2):165-70.

15 Santoro N, Amato A, Grandone A, Brienza C, Savarese P, Tartaglione N, et al. Predicting metabolic syndrome in obese children and adolescents: look, measure and ask. Obes Facts. 2013;6(1):48-56.

16 Atabek ME, Selver Eklioglu B, Akyürek N. Which metabolic syndrome criteria best predict non-alcoholic fatty liver disease in children? Eat Weight Disord. 2014 Dec;19(4):495-501.

17 Vukovic R, Zdravkovic D, Mitrovic K, Milenkovic T, Todorovic S, Vukovic A, et al. Metabolic syndrome in obese children and adolescents in Serbia: prevalence and risk factors. J Pediatr Endocrinol Metab. 2015 Jul;28(7-8):903-9.

18 Sewaybricker LE, Antonio MÂRGM, Mendes RT, Barros Filho AA, Zambon MP. Metabolic syndrome in obese adolescents: what is enough? Rev Assoc Med Bras (1992). 2013;59(1):64-71.

19 Rank M, Siegrist M, Wilks DC, Langhof H, Wolfarth B, Haller B, et al. The cardio-metabolic risk of moderate and severe obesity in children and adolescents. J Pediatr. 2013 Jul;163(1):137-42.

20 İnanç BB. Metabolic syndrome in school children. J Clin Res Pediatr Endocrinol. 2013;5(2):140-1.

21 Makkes S, Renders CM, Bosmans JE, van der Baan-Slootweg OH, Seidell JC. Cardiometabolic risk factors and quality of life in severely obese children and adolescents in The Netherlands. BMC Pediatr. 2013 Apr;13(1):62.

22 Park J, Hilmers DC, Mendoza JA, Stuff JE, Liu Y, Nicklas TA. Prevalence of metabolic syndrome and obesity in adolescents aged 12 to 19 years: comparison between the United States and Korea. J Korean Med Sci. 2010 Jan;25(1):75-82.

23 Kurtoglu S, Akin L, Kendirci M, Hatipoglu N, Elmali F, Mazicioglu M. The absence of insulin resistance in metabolic syndrome definition leads to underdiagnosing of metabolic risk in obese patients. Eur J Pediatr. 2012 Sep;171(9):1331-7.

24 Chedjou-Nono E, Sap S, Choukem SP, Ngosso Tetanye I, Nebongo D, Koki Ndombo O. Cardiometabolic profile of obese children in a sub-Saharan African setting: a cross-sectional study. BMC Pediatr. 2017 May;17(1):129.

25 Masquio DC, de Piano-Ganen A, Oyama LM, Campos RM, Santamarina AB, de Souza GI, et al. The role of free fatty acids in the inflammatory and cardiometabolic profile in adoles- cents with metabolic syndrome engaged in interdisciplinary therapy. J Nutr Biochem. 2016 Jul;33:136-44.

26 Wilmot EG, Edwardson CL, Biddle SJ, Gorely T, Henson J, Khunti K, et al. Prevalence of diabetes and impaired glucose metabolism in younger 'at risk' UK adults: insights from the STAND programme of research. Diabet Med. 2013 Jun;30(6):671-5.

27 Alattar A, Al-Majed H, Almuaili T, Almutairi O, Shaghouli A, Altorah W. Prevalence of impaired glucose regulation in asymptomatic Kuwaiti young adults. Med Princ Pract. 2012;21(1):51-5.

28 Lopez-Capape $M$, Alonso M, Colino E, Mustieles C, Corbaton J, Barrio R. Frequency of the metabolic syndrome in obese Spanish pediatric population. Eur J Endocrinol. 2006 Aug;155(2):313-9.

29 Körner A, Wiegand S, Hungele A, Tuschy S, Otto KP, l'Allemand-Jander D, et al.; APV initiative; German Competence Net Obesity. Longitudinal multicenter analysis on the course of glucose metabolism in obese children. Int J Obes. 2013 Jul;37(7):931-6.

30 Luksiene DI, Baceviciene M, Tamosiūnas A, Cerniauskiene LR, Margeviciene L, Reklaitiene R. Prevalence of the metabolic syndrome diagnosed using three different definitions and risk of ischemic heart disease among Kaunas adult population. Medicina (Kaunas). 2010;46(1):61-9.

31 Smetanina N, Albaviciute E, Babinska V, Karinauskiene L, Albertsson-Wikland $\mathrm{K}, \mathrm{Pe}$ trauskiene A, et al. Prevalence of overweight/ obesity in relation to dietary habits and lifestyle among 7-17 years old children and adolescents in Lithuania. BMC Public Health. 2015 Oct;15(1):1001.

32 Flynn JT, Kaelber DC, Baker-Smith CM, Blowey D, Carroll AE, Daniels SR, et al.; Subcommittee on Screening and Management of High Blood Pressure in Children. Clinical Practice Guideline for Screening and Management of High Blood Pressure in Children and Adolescents. Pediatrics. 2017 Sep;140(3):e20171904.

33 Emmanuel M, Bokor BR. Tanner Stages. In: StatPearls. Edn. Treasure Island (FL); 2019.

34 Cole TJ, Lobstein T. Extended international (IOTF) body mass index cut-offs for thinness, overweight and obesity. Pediatr Obes. 2012 Aug;7(4):284-94.

35 Nawarycz LO, Krzyzaniak A, StawińskaWitoszyńska B, Krzywińska-Wiewiorowska M, Szilagyi-Pagowska I, Kowalska M, et al. Percentile distributions of waist circumference for 7-19-year-old Polish children and adolescents. Obes Rev. 2010 Apr;11(4):281-8.

36 Craig ME, Hattersley A, Donaghue K; International Society for Pediatric and Adolescent Diabetes. ISPAD Clinical Practice Consensus Guidelines 2006-2007. Definition, epidemiology and classification. Pediatr Diabetes. 2006 Dec;7(6):343-51. 
37 Soonthornpun S, Setasuban W, Thamprasit A, Chayanunnukul W, Rattarasarn C, Geater A. Novel insulin sensitivity index derived from oral glucose tolerance test. J Clin Endocrinol Metab. 2003 Mar;88(3):1019-23.

38 Singh B, Saxena A. Surrogate markers of insulin resistance: A review. World J Diabetes. 2010 May;1(2):36-47.

39 Radikova Z. Assessment of insulin sensitivity/ resistance in epidemiological studies. Endocr Regul. 2003 Sep;37(3):189-94.

40 Lorenzo C, Haffner SM, Stančáková A, Kuusisto J, Laakso M. Fasting and OGTT-derived measures of insulin resistance as compared with the euglycemic-hyperinsulinemic clamp in nondiabetic Finnish offspring of type 2 diabetic individuals. J Clin Endocrinol Metab. 2015 Feb;100(2):544-50.

41 Gutt M, Davis CL, Spitzer SB, Llabre MM, Kumar M, Czarnecki EM, et al. Validation of the insulin sensitivity index $(\operatorname{ISI}(0,120))$ : comparison with other measures. Diabetes Res Clin Pract. 2000 Mar;47(3):177-84.

42 Sarah de Ferranti JWN. Definition and screening for dyslipidaemia in children. UpToDate 2013.

43 Ng M, Fleming T, Robinson M, Thomson B, Graetz N, Margono C, et al. Global, regional, and national prevalence of overweight and obesity in children and adults during 19802013: a systematic analysis for the Global Burden of Disease Study 2013. Lancet. 2014 Aug;384(9945):766-81.

44 Janssen I, Katzmarzyk PT, Boyce WF, Vereecken C, Mulvihill C, Roberts C, et al.; Health Behaviour in School-Aged Children Obesity Working Group. Comparison of overweight and obesity prevalence in school-aged youth from 34 countries and their relationships with physical activity and dietary patterns. Obes Rev. 2005 May;6(2):123-32.

45 Sangun Ö, Dündar B, Köşker M, Pirgon Ö, Dündar N. Prevalence of metabolic syndrome in obese children and adolescents using three different criteria and evaluation of risk factors. J Clin Res Pediatr Endocrinol. 2011;3(2):70-6.

46 Rizzo AC, Goldberg TB, Silva CC, Kurokawa CS, Nunes HR, Corrente JE. Metabolic syndrome risk factors in overweight, obese, and extremely obese Brazilian adolescents. Nutr J. 2013 Jan;12(1):19.

47 Jamoussi H, Mahjoub F, Sallemi H, Berriche O, Ounaissa K, Amrouche C, et al. Metabolic syndrome in Tunisian obese children and adolescents. Tunis Med. 2012 Jan;90(1):36-40.
48 Bustos P, Saez K, Gleisner A, Ulloa N, Calvo C, Asenjo S. Metabolic syndrome in obese ad olescents. Pediatr Diabetes. 2010 Feb;11(1):55-60.

49 Jung C, Fischer N, Fritzenwanger M, Figulla HR. Anthropometric indices as predictors of the metabolic syndrome and its components in adolescents. Pediatr Int. 2010 Jun;52(3): 402-9.

50 Laurson KR, Welk GJ, Eisenmann JC. Diagnostic performance of BMI percentiles to identify adolescents with metabolic syndrome. Pediatrics. 2014 Feb;133(2):e330-8.

51 Ervin RB. Prevalence of metabolic syndrome among adults 20 years of age and over, by sex, age, race and ethnicity, and body mass index: United States, 2003-2006. Natl Health Stat Report. 2009 May;(13):1-7.

52 Biro FM, Huang B, Morrison JA, Horn PS Daniels SR. Body mass index and waist-toheight changes during teen years in girls are influenced by childhood body mass index. J Adolesc Health. 2010 Mar;46(3):245-50.

53 Demerath EW, Schubert CM, Maynard LM, Sun SS, Chumlea WC, Pickoff A, et al. Do changes in body mass index percentile reflect changes in body composition in children? Data from the Fels Longitudinal Study. Pediatrics. 2006 Mar;117(3):e487-95.

54 Zeve D, Tang W, Graff J. Fighting fat with fat: the expanding field of adipose stem cells. Cell Stem Cell. 2009 Nov;5(5):472-81.

55 Virtue S, Vidal-Puig A. It's not how fat you are, it's what you do with it that counts. PLoS Biol. 2008 Sep;6(9):e237.

56 Smorlesi A, Frontini A, Giordano A, Cinti S. The adipose organ: white-brown adipocyte plasticity and metabolic inflammation. Obes Rev. 2012 Dec;13(Suppl 2):83-96

57 Makki K, Froguel P, Wolowczuk I. Adipose tissue in obesity-related inflammation and insulin resistance: cells, cytokines, and chemokines. ISRN Inflamm. 2013 Dec;2013:139239.

58 Kurtoglu S, Akin L, Kendirci M, Hatipoglu N, Elmali F, Mazicioglu M. The absence of insulin resistance in metabolic syndrome definition leads to underdiagnosing of metabolic risk in obese patients. Eur J Pediatr. 2012 Sep;171(9):1331-7.

59 Yin J, Li M, Xu L, Wang Y, Cheng H, Zhao X, et al. Insulin resistance determined by Homeostasis Model Assessment (HOMA) and associations with metabolic syndrome among Chinese children and teenagers. Diabetol Metab Syndr. 2013 Nov;5(1):71.

60 DeBoer MD, Gurka MJ. Low sensitivity of the metabolic syndrome to identify adolescents with impaired glucose tolerance: an analysis of NHANES 1999-2010. Cardiovasc Diabetol. 2014 Apr;13(1):83.
61 Raitakari OT, Porkka KV, Rönnemaa T, Knip M, Uhari M, Akerblom HK, et al. The role of insulin in clustering of serum lipids and blood pressure in children and adolescents. The Cardiovascular Risk in Young Finns Study. Diabetologia. 1995 Sep;38(9):1042-50.

62 Moran A, Jacobs DR Jr, Steinberger J, Hong $\mathrm{CP}$, Prineas R, Luepker R, et al. Insulin resistance during puberty: results from clamp studies in 357 children. Diabetes. 1999 Oct;48(10):2039-44.

63 George L, Bacha F, Lee S, Tfayli H, Andreatta E, Arslanian S. Surrogate estimates of insulin sensitivity in obese youth along the spectrum of glucose tolerance from normal to prediabetes to diabetes. J Clin Endocrinol Metab. 2011 Jul;96(7):2136-45.

64 van der Aa MP, Fazeli Farsani S, Knibbe CA, de Boer A, van der Vorst MM. PopulationBased Studies on the Epidemiology of Insulin Resistance in Children. J Diabetes Res. 2015;2015:362375.

65 Kurtoğlu S, Hatipoğlu N, Mazıcıoğlu M, Kendirici M, Keskin M, Kondolot M. Insulin resistance in obese children and adolescents: HOMA-IR cut-off levels in the prepubertal and pubertal periods. J Clin Res Pediatr Endocrinol. 2010;2(3):100-6.

66 Casavalle PL, Lifshitz F, Romano LS, Pandolfo M, Caamaño A, Boyer PM, et al. Prevalence of dyslipidemia and metabolic syndrome risk factor in overweight and obese children. Pediatr Endocrinol Rev. 2014 Dec;12(2):213-23.

67 Mellerio H, Alberti C, Druet C, Capelier F, Mercat I, Josserand E, et al. Novel modeling of reference values of cardiovascular risk factors in children aged 7 to 20 years. Pediatrics. 2012 Apr;129(4):e1020-9.

68 Pinhas-Hamiel O, Lerner-Geva L, Copperman NM, Jacobson MS. Lipid and insulin levels in obese children: changes with age and puberty. Obesity (Silver Spring). 2007 Nov;15(11):2825-31.

69 Burns SF, Lee SJ, Arslanian SA. Surrogate lipid markers for small dense low-density lipoprotein particles in overweight youth. J Pediatr. 2012 Dec;161(6):991-6.

70 Hannon TS, Bacha F, Lee SJ, Janosky J, Arslanian SA. Use of markers of dyslipidemia to identify overweight youth with insulin resistance. Pediatr Diabetes. 2006 Oct;7(5):260-6.

71 Vukovic R, Mitrovic K, Milenkovic T, Todorovic S, Soldatovic I, Sipetic-Grujicic S, et al. Insulin-sensitive obese children display a favorable metabolic profile. Eur J Pediatr. 2013 Feb;172(2):201-6. 